\title{
Academic dishonesty and whistle-blowing in a higher education institution: A sociological analysis
}

Authors:

Mr Ugljesa Radulovic ${ }^{1}$

Prof. Tina Uys ${ }^{1}$

Affiliation:

${ }^{1}$ University of Johannesburg, South Africa

Corresponding author:

Mr Ugljesa Radulovic ugljesar@gmail.com

DOI:

$10.15249 / 13-2-218$

\section{Keywords:}

academic dishonesty; higher education; reasoned action approach; whistleblowing

\section{Abstract}

High rates of academic dishonesty are a concern in South Africa and worldwide, and whistle-blowing is a mechanism that can be employed to curb its incidence. This study tested the relationship between factors that influence the willingness of students at a South African higher education institution to blow the whistle on perceived academic dishonesty. A sample of 405 undergraduate sociology students at a South African university completed the self-administered structured questionnaires. The study found that students who feared retaliation from wrongdoers were less likely to be willing to report severe academic dishonesty. Students who were more likely to report on both severe and less severe forms of wrongdoing were those with higher levels of general honesty, those with higher levels of academic honesty, and those who were highly influenced by adherence to principles when deciding whether to report.

\section{Introduction}

Academic dishonesty is a commonly occurring phenomenon faced by higher education institutions globally (McCabe, Trevino \& Butterfield, 2001; Hutton, 2006; De Bruin \& Rudnick, 2007; Caldwell, 2010). Research conducted at universities across the United States indicated that as much as $90 \%$ of students engage in academic dishonesty (Rabi, Patton, Fjortoft \& Zgarrick, 2006:1). Similarly, in an analysis of a range of different studies, Seals, Hammons and Mamiseishvili (2014:26) found that academic dishonesty was rife at university campuses.

Academic dishonesty is generally defined as behaviour that consciously contravenes the requirement that work submitted 
for the purposes of assessment was a student's own work (De Lambert, Ellen \& Taylor, 2003:98). The most commonly occurring forms of academic dishonesty are plagiarism (copying sentences from others' published work without the correct and required citations) and cheating in tests or examinations. Other forms include gaining access to examination papers in advance of the examination being written, as well as working with others on the completion of an assignment that should have been completed individually (Eastman, Eastman \& lyer, 2008:211).

South African universities also seem to display a high prevalence of academic dishonesty. Research at a university in Johannesburg, South Africa, showed that a large proportion (approximately $38 \%$ of the student respondents) had engaged in academic dishonesty on at least one occasion in their academic careers (De Bruin \& Rudnick, 2007:160). Data released by the Department of Student Ethics and Judicial Services (2014:1) at the University of Johannesburg (UJ) indicated that during both the first and second terms of 2014, academic transgressions constituted the majority of disciplinary cases.

A study exploring the views of first-year students at a South African university with regard to academic ethics displayed an ambivalence with regard to which actions signify academic honesty or dishonesty (Thomas \& Van Zyl, 2012:151). Finchilescu and Cooper (2018:296) distinguished between three perspectives towards academic dishonesty as indicated by a sample of first-year undergraduate psychology students at a South African university. The first group viewed academic dishonesty as a moral transgression that is clearly wrong and infringes upon ethical principles. The second group displayed pressure transgression that viewed academic dishonesty as resulting from pressures students have to manage with regard to university and family expectations. The third group considered academic dishonesty to be unintentional and mainly resulting from a confusion with regard to rules related to cheating as well as inconsistency in implementing the rules. This is called confused transgression.

Another study conducted amongst academic staff at a South African university showed that they were aware of the high prevalence of academic dishonesty at the university (Thomas \& De Bruin, 2012:13). They were knowledgeable about the seriousness of academic dishonesty, but few of them were willing to act against such behaviour (Thomas \& De Bruin, 2012:20).

Academic institutions worldwide attempt to implement mechanisms to combat the problem of academic dishonesty endemic to many of them. Academic institutions in South Africa, similarly, place a high premium on academic honesty and use various mechanisms to increase the awareness thereof (Thomas \& De Bruin, 2012:22). UJ's plagiarism policy (2013:1), for example, indicates that academic honesty and integrity are preconditions for fulfilling an ideal of research credibility. It identifies plagiarism "as a worldwide phenomenon", which is a threat to UJ's "goal of realising the highest international standards of academic and professional performance". The UJ plagiarism policy (2013:1) attempts to combat plagiarism through instilling ethical values, academic honesty and integrity; and through preventing and managing acts of plagiarism. 
Whistle-blowing presents itself as a mechanism to remedy wrongdoing such as academic dishonesty. Whistle-blowing is generally seen as an act where information about perceived organisational wrongdoing is reported to superiors by organisational members (Uys, 2008:904). The disclosure recipient is an entity who is perceived to have the potential to remedy the wrongdoing (Jubb, 1999:83). An internal disclosure recipient is someone within the confines of the organisation who receives the disclosure (Jubb, 1999:90), whilst an external disclosure recipient is an individual outside of the respective organisation who possesses the necessary power to expose and rectify the situation that has occurred (Miceli \& Near, 1992). In addressing academic dishonesty at a university one possible route would be to encourage students (and staff) to expose perceived cases of dishonesty by raising their concerns informally (through a discussion with the student who committed academic dishonesty for example) or by employing formal routes (reporting the student who committed academic dishonesty to a relevant institutional authority).

This study focuses on testing the relationship between factors that influence the likelihood that students at a South African higher education institution would blow the whistle on academic dishonesty that they become aware of. As far as could be determined no study of this kind has yet been conducted at a South African university. The factors that are considered in this study are identified in the literature review that follows.

\section{Literature review \\ 2.1 The intention to blow the whistle: the reasoned action approach}

The reasoned action approach argues that background factors culminate in an individual's experience of the social world, which determines their behavioural beliefs, normative beliefs and control beliefs (Fishbein \& Ajzen, 2010:16). Behavioural beliefs are the beliefs that an individual holds "about the positive or negative consequences they might experience if they performed the behaviour", and these behavioural beliefs determine an individual's attitude towards the behaviour (Fishbein \& Ajzen, 2010:16). Observers of wrongdoing in an organisation would therefore evaluate the possible consequences of making a disclosure or not making a disclosure, on the basis of which they would form a favourable or unfavourable attitude towards engaging in whistle-blowing.

Normative beliefs are beliefs of how one might be evaluated by an 'important' individual or group when performing a certain behaviour. Individuals develop perceptions with regard to how their significant others would respond, should they engage in this behaviour, and whether these significant others are likely to engage in the behaviour themselves. Through these injunctive and descriptive normative beliefs actors develop a perceived norm with regard to the behaviour, which refers to the social pressure experienced to act in a particular way as well as the individual's motivation to conform to the expectations of significant others. Observers of organisational wrongdoing would therefore be more 
likely to form an intention to blow the whistle if they feel that people whose opinions they value would approve of them doing so (Fishbein \& Ajzen, 2010:16). In the case of academic dishonesty, the extent to which the university has established the normative belief that it is right to report academic dishonesty and that reporting would result in a positive evaluation from 'important' individuals or groups (i.e. academic staff) would play an important role in whether students would view whistle-blowing on dishonesty as acting in good faith. Thus, a perceived norm manifests that it is right to report academic dishonesty; however, not all students accept such a norm.

Control beliefs are the "beliefs about personal and environmental factors that can help or impede their [an individual's] attempts to carry out the behaviour", and results in one's perception of self-efficacy or perceived behavioural control (Fishbein \& Ajzen, 2010:16). Perceived behavioural control is an individual's perception of the degree of control possessed to act out a specific behaviour. This entails weighing up the availability of the resources and opportunities needed to perform certain behaviours as well as the constraints and risks associated with those behaviours. These control beliefs result in the individual developing a sense of perceived behavioural control. In the case of whistle-blowing organisational obstacles such as management intentionally ignoring or frustrating the reporting of wrongdoing, the belief that it is impossible to correct the wrongdoing through reporting, and concerns about the possibility of retaliation could all act as control factors that discourage potential whistle-blowers.

This set of factors, namely an individual's attitude towards the behaviour, perceived norms and perceived behavioural control determines intention, and in turn, predicts an individual's behaviour (Fishbein \& Ajzen, 2010:16-18). People with favourable attitudes towards whistle-blowing, who perceive the organisational norms to be supportive, and who believe that they are in control of the situation, are therefore more likely to have a strong intention to blow the whistle on organisational wrongdoing. According to Fishbein and Azjen (2010:21) the strength of the intention is directly related to the likelihood that the behaviour will be executed.

However, the actual control that people have over carrying out their intentions, particularly whether they have the required skills and abilities, or whether environmental constraints are preventing them from performing the actions, should be taken into account when attempting to predict whether their intentions would translate into actions (Fishbein \& Ajzen, 2010:17). It is important to note that actual control such as an obligation to respect academic honour codes, stronger institutional requirements and encouragement to report academic dishonesty can have a direct impact on reporting. Larmer (1992) places great emphasis in his argument on loyalty, and that loyalty (or rather the individual's definition of loyalty and the situational and organisational emphasis placed on loyalty) will determine whether an individual will be inclined to become a whistle-blower. The extent to which a student identifies with an institution, and in turn exhibits loyalty towards that institution, will determine the extent to which they are willing to report wrongdoing within the respective institution. 
When considering factors influencing the intention to report academic dishonesty, behavioural beliefs are the beliefs associated with the perceived consequences of reporting academic dishonesty. These beliefs entail the consequences of reporting and are impacted by factors such as a fear of retaliation. If a student feels that the potential negative consequences of retaliation such as labelling, victimisation and ostracising will follow, that student will develop an attitude that is inclined not to report academic dishonesty. Whether an individual is likely to become a whistle-blower is greatly determined by the policy of the institution they reside in (Callahan \& Collins, 1992). An institution that wishes to encourage whistle-blowing will promote a policy that protects the whistle-blower from retaliation. Mesmer-Magnus and Viswesvaran (2005:280) provide evidence that contextual factors are linked to whistle-blowing and add that "potential whistleblowers who perceive a threat of retaliation ... are much less likely to blow the whistle". Students who are encouraged by the institution to blow the whistle would be more likely to do so. However, a deterrent to blowing the whistle could come in the form of potential retaliation. Elliston (1982) emphasises the importance of ensuring the anonymity of the whistle-blower, by claiming that members of organisations where the identity of the whistle-blower is protected will be more likely to blow the whistle on perceived wrongdoing.

A study at a large Midwest university in the USA (Henningsen, Valde \& Denbow, 2013:154-161) found that students were more likely to blow the whistle on those who committed academic dishonesty if they attended the same classes as they did, as opposed to those not attending the same classes. This indicates that students were more willing to report on those students who were in academic competition with them than those who were not.

Research in England and Wales noted that colleges provided information about whistle-blowing procedures through employee handbooks, but the most common methods at universities is via institution-related web pages (Lewis, Ellis, Kyprianou \& Homewood, 2001:223). With the provision of such a resource via easily accessible Internet links, a student's access to resources, in terms of blowing the whistle, is increased. Ultimately, the access to resources increases a student's degree of comfort (due to ease of access) when faced with the dilemma of blowing the whistle. These students who report academic dishonesty "participate in the creation of [a] moral context" (McCabe et al., 2001:32). It is therefore important to consider how students' level of morality influences their willingness to blow the whistle.

\subsubsection{Morality}

Research conducted amongst undergraduate students at a Midwestern university (USA), showed that students displaying a higher degree of morality were more likely to blow the whistle on academic dishonesty to the faculty (Henningsen et al., 2013:162). A higher degree of morality is typically dictated by one's awareness of what is right and wrong, thus the individual exercises general honesty. 
Whistle-blowers could emerge when an individual considers that there is an "ethical conflict between personal and organization values" (Jubb, 1999:78). According to this argument, an individual, who might be more inclined to become a whistle-blower, is one who occupies a position that he or she feels might conflict with their personal values or ethics. For example, it would be interesting to determine whether a student with a high degree of morality who is delegated to doing academic group work with other students committing academic dishonesty, would be likely to report this dishonesty.

\subsubsection{Academic dishonesty}

Research at Dundee Medical School in the United Kingdom showed that students generally considered dishonest behaviour such as "copying in exams, submitting a senior student's work, or copying another student's work" (Rennie \& Crosby, 2001:275) to be wrong. However, certain acts, such as plagiarising, were not considered to be dishonest (Rennie \& Crosby, 2001:274-275). This leads Rennie and Crosby (2001:275) to conclude that "scenarios involving plagiarism may indicate students' lack of understanding regarding referencing". Thus, a reason why students commit academic dishonesty is because they do not understand which behaviours qualify as academic dishonesty. If students are unable to identify what behaviours should be viewed as dishonest or do not consider these actions as serious, they are less likely to blow the whistle on these behaviours.

Research has also indicated that students would be more likely to engage in cheating behaviour if they consider it acceptable or in line with the subjective norm. McCabe and Trevino (1997:392) argued that students in the United States were likely to engage in academic dishonesty in "environments where peers are cheating and where peer disapproval of cheating is low". A norm of cheating often develops if students observe their peers engaging in such behaviour, especially if they refrain from confronting their peers or blowing the whistle to university authorities (Henningsen et al., 2013:149).

While this study does not focus on reasons why students engage in dishonest behaviour, it is reasonable to expect that students who do not consider certain actions to be dishonest, would also not be likely to blow the whistle on those actions. Also, if students develop justifications for why they engage in academically dishonest behaviour, they will probably not be willing to report others who are engaging in such behaviours.

\subsubsection{Justification of academic dishonesty}

Almost $70 \%$ of the students who participated in a study by Monica, Ankola, Ashokkumar and Hebbal (2010:79) had previously committed academic dishonesty and felt that cheating would not have any significant effect on their futures. They gave a "fear of failure" as a justification for committing academic dishonesty (Monica et al., 2010:81). The fear of failure is a by-product of the pressure to succeed, hence the two motives are directly related.

Rennie and Rudland's (2003:97) study conducted in Scotland indicated that pressures to succeed result in students' engagement in various forms of academic misconduct. Additionally, Hutton (2006:171) identified various reasons, using empirical evidence, for academic dishonesty in her study concerning college students. The main reasons for 
cheating included laziness, wanting to achieve higher grades, and pressures to succeed. In this study half of the students did not believe that academic dishonesty was an immoral act. This could result in students developing justifications for engaging in activities that are generally considered to be dishonest. Justifications for academic dishonesty would also make it less likely that students would report on these actions.

\subsubsection{Personal consequences of reporting}

The willingness to report academic dishonesty can also be greatly influenced by a fear of wrongdoer retaliation. Uys (2008:905) identifies a number of actions that wrongdoers use to exact revenge on the whistle-blower, for being reported on. These entail the isolation of the whistle-blower; a reduction in friendliness towards the whistle-blower; labelling the whistle-blower as a 'troublemaker'; and stonewalling the whistle-blower (Uys, 2008:905).

This research has not located literature with regard to retaliation against students reporting academic dishonesty of their peers. However, whistle-blower retaliation has been identified in other contexts. Black's (2011:26) research conducted amongst nurses in the USA indicated that the most frequent response for not reporting wrongdoing was a 'fear of retaliation'.

Retaliation due to peer-reported academic dishonesty can manifest in the form of labelling, victimisation or ostracising (as identified in other contexts). The fear of such retaliation can directly impact a student's willingness to report academic dishonesty.

\subsubsection{Adherence to principles}

Morality of loyalty should compel a student to expose a wrongdoing occurring in the organisation of a higher learning institution. Loyalty is the obligation to protect the reputation of an organisation by acting in good faith and reporting a wrongdoing incident (Uys \& Senekal, 2008:38). Being loyal means that organisational members are expected to obey any reasonable instruction. They are also required to abide by the values and norms of the organisation. Protecting and promoting the reputation of the organisation is another aspect of organisational loyalty, while organisational members are also expected to maintain confidentiality (Uys, 2008:907).

As is clear from the above overview of the literature, no similar study has been conducted at a South African university. This makes it important to test the following hypotheses in the South African context:

- Hypothesis 1: There is a statistically significant relationship between the level of general dishonesty of students and their willingness to report academic dishonesty.

- Hypothesis 2: There is a statistically significant relationship between the level of students' academic dishonesty and their willingness to report academic dishonesty.

- Hypothesis 3: There is a statistically significant relationship between the extent to which students justify dishonest behaviours and their willingness to report academic dishonesty. 
- Hypothesis 4: There is a statistically significant relationship between students' motivations for reporting dishonest behaviours and their willingness to report academic dishonesty.

3. Method

Using a quantitative approach, the research measured University of Johannesburg sociology students' attitudes to perceived academic dishonesty, as well as the extent to which they were willing to engage in whistle-blowing within the institution. Data was collected utilising a self-administered questionnaire which was distributed electronically via the University of Johannesburg's academic internet portal 'Blackboard'. A census was used for the purposes of the research, to counteract the tendency of a low response rate with self-administered questionnaires (Bourque \& Fielder, 2003:154). Thus, the link to the online questionnaire was distributed to the entire undergraduate sociology population rather than drawing a sample. This proved more effective as sample loss did not have as significant an effect. The biographic characteristics of the sample respondents were compared statistically to the entire undergraduate sociology population at this university to determine whether the sample was representative of the population. A total of 405 respondents completed the questionnaire, which gave a response rate of $20.52 \%$.

Close-ended questions were used in the questionnaire and were based on the findings of studies in the body of literature. The Likert-type scale was employed where respondents expressed their attitudes in terms of ordinal-level categories that are ranked along a continuum. The data was analysed by using SPSS 22. Inferential statistics such as the Chi-Square Test of Independence; the $t$-test; analysis of variance (ANOVA); and Pearson's $r$-test were used to test the hypotheses (Bless \& Kathuria, 1993:85).

Factor analysis and item analysis providing the Cronbach's alpha internal consistency measure ensured the validity and reliability of the scales developed during the data analysis. Exploratory factor analysis was used to create the scales measuring the dimensions of whistle-blowing which resulted in the reduction of items to fewer, more interpretable factors (Eiselen \& Uys, 2016:108), thus enabling a construction of two or more continuous scales for the purposes of hypothesis testing. Principal Axis Factoring was used as the extraction method as it is able to better "recover weak factors" and ensure "that the maximum likelihood estimator is asymptotically efficient" (de Winter \& Dodou, 2012:695). The Oblimin with Kaiser Normalisation rotation method was used. For the the Kaiser-Meyer-Olkin Measure of Sampling Adequacy (KMO), a value of 0.6 is needed for there to be sufficient correlation between the pairs of items in order to proceed with further factor analysis. Additionally, the Bartlett's Test of Sphericity needs to reject the null-hypothesis to ensure that the items are uncorrelated so that factor analysis can continue (Eiselen \& Uys, 2016:111), and a $p$-value smaller than 0.05 will ensure this. The Measure of Sampling Adequacy (MSA) needs to exceed 0.6. The inter-item reliability was determined utilising Cronbach's alpha. A Cronbach's alpha reliability coefficient of 0.7 or higher is considered acceptable for the purposes of social science research. 


\subsection{Willingness to report academic dishonesty}

This factor analysis dealt with the willingness to report academic dishonesty and was measured using questions pertaining to students' most likely immediate actions when encountering academic dishonesty. The questions aimed to determine what students' most likely response would be in a set of scenarios. They were provided with the following possible responses: $1=$ 'keep quiet'; $2=$ 'talk to the offender'; $3=$ 'discuss your concerns with other students'; 4 = 'discuss your concerns with an appropriate authority within your given academic institution'; and 5 = 'discuss with an individual in authority outside of your given academic institution'. These responses indicate a progression from not taking any reporting action, to reporting internally and lastly to reporting externally. The scale measures to what extent students are willing to take active measures. As the scale progresses, the possible consequences become more serious for the wrongdoer as well as the whistle-blower.

Table 1 indicates the two factors that were created. Factor one is the willingness to report severe academic dishonesty. Factor two is the willingness to report less severe academic dishonesty. A high value on both these factors indicates a willingness to report academic dishonesty.

Table 1: Pattern matrix - willingness to report academic dishonesty

\begin{tabular}{|c|c|c|}
\hline & \multicolumn{2}{|c|}{ Factor } \\
\hline & 1 & 2 \\
\hline 1. You notice that a fellow student has brought notes into the test or exam & 0.924 & \\
\hline $\begin{array}{l}\text { 2. You notice that a fellow student is using their cellular phone during a test or } \\
\text { exam (for what appears to be cheating) }\end{array}$ & 0.894 & \\
\hline 3. You notice that a student is cheating during a test or exam & 0.892 & \\
\hline $\begin{array}{l}\text { 4. You become aware that a student has gained access to a test or exam prior to it } \\
\text { being written }\end{array}$ & 0.692 & \\
\hline $\begin{array}{l}\text { 5. You become aware that a fellow student has used a senior student's assignment } \\
\text { for submission as their own }\end{array}$ & 0.583 & \\
\hline $\begin{array}{l}\text { 6. You become aware that a fellow student has deliberately not referenced others' } \\
\text { published work in their assignment }\end{array}$ & & 0.890 \\
\hline 7. A fellow student receives help from someone else in writing parts of an essay & & 0.833 \\
\hline $\begin{array}{l}\text { 8. You become aware that a fellow student created fake sources for their } \\
\text { assignment }\end{array}$ & & 0.805 \\
\hline 9. You become aware that a fellow student's essay was written by someone else & & 0.632 \\
\hline
\end{tabular}


Figure 1 indicates that the distribution of the sample responses for the willingness to report severe academic dishonesty is positively skewed. The mean of responses for the willingness to report severe academic dishonesty was 2.67 , thus fewer than half of the respondents were likely to respond to perceived severe academic dishonesty beyond speaking to the wrongdoer.

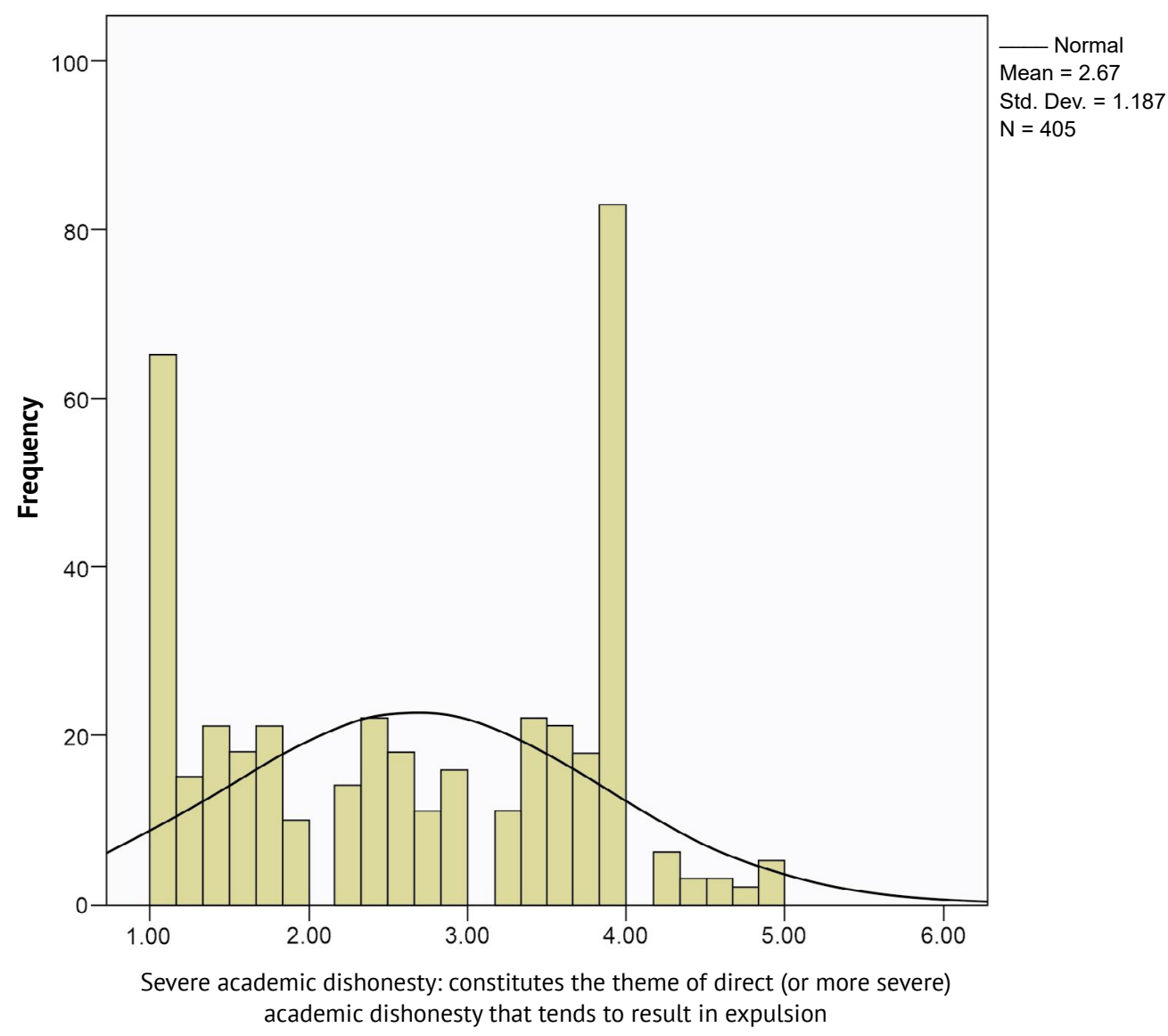

Figure 1: Histogram - willingness to report severe academic dishonesty 
Figure 2 indicates that the distribution of the sample responses for the willingness to report less severe academic dishonesty is positively skewed. The mean of responses for the willingness to report less severe academic dishonesty was 2.06, thus fewer than half of the respondents were likely to do more than speak to the wrongdoer if they became aware of less severe academic dishonesty.

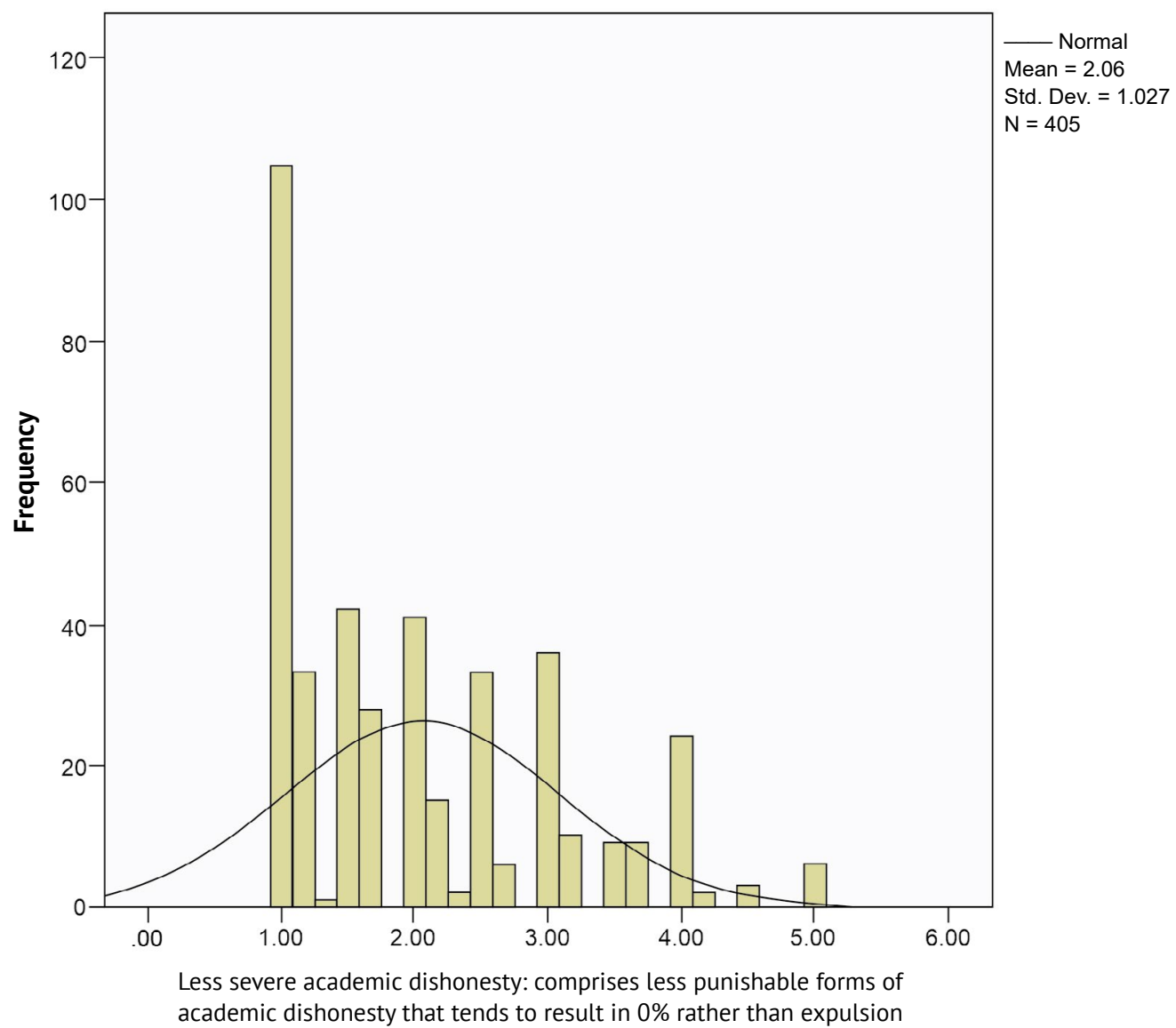

Figure 2: Histogram - willingness to report less severe academic dishonesty

The results indicated that there were at least some students who were willing to report academic dishonesty, however these were only a small number. Two factors have been identified: willingness to report severe academic dishonesty and willingness to report less severe academic dishonesty. Students were generally not inclined to engage in internal whistle-blowing with regard to severe academic dishonesty. Generally, students were at most only willing to talk to the offender. The students were even less likely to engage in the internal reporting of less severe academic dishonesty.

\subsection{Students' levels of general honesty}

This factor analysis dealt with students' varying degrees of morality and was measured using questions pertaining to general honesty. The questions aimed to determine the 
students' degree of general honesty. The students were asked to indicate to what extent they considered certain actions acceptable and were provided with the following possible responses: 1 = 'completely acceptable'; 2 = 'somewhat acceptable'; 3 = 'neither acceptable not unacceptable'; 4 ='somewhat unacceptable'; and 5='completely unacceptable'. A high value on this factor indicates a high level of general honesty.

Table 2: Pattern matrix - general honesty

\begin{tabular}{|l|c|}
\hline & Factor \\
\cline { 2 - 2 } 1. Offering a bribe to a traffic officer in order to avoid a fine & 1 \\
\hline 2. Illegally downloading music or movies from the internet & 0.681 \\
\hline 3. Bending the truth a little in order to receive a bursary & 0.669 \\
\hline 4. Taking stationery, such as pens and pencils, from an employer & 0.555 \\
\hline Cronbach's alpha Factor 1 = 0.711 & 0.507 \\
\hline
\end{tabular}

Figure 3 indicates that the distribution of the sample responses for general honesty is negatively skewed. The mean of responses for general honesty was 3.77 , thus the average student tended towards a higher degree of general honesty.

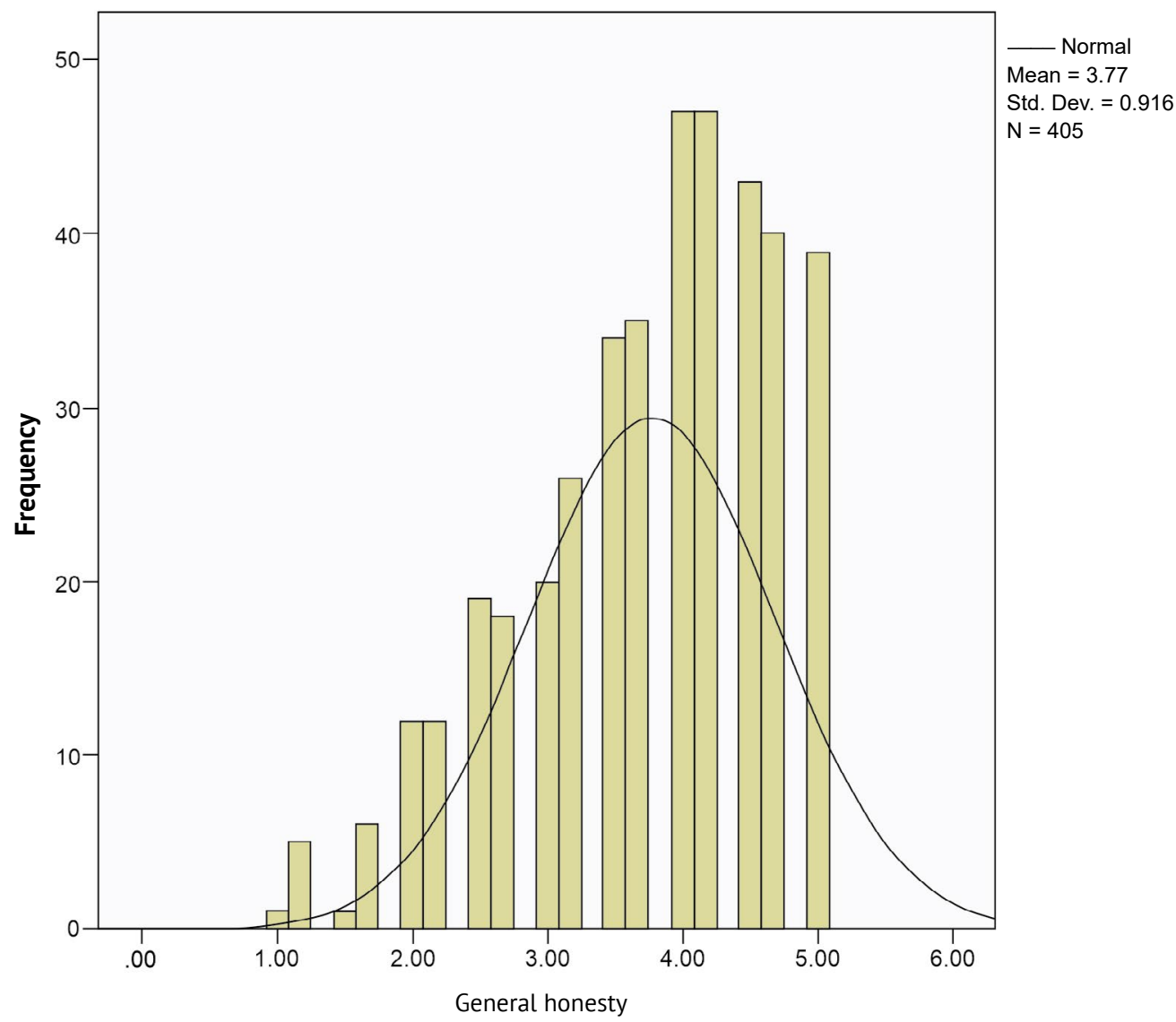

Figure 3: Histogram - general honesty 
One factor has been identified: general honesty. It identifies that there is a relatively high level of honesty amongst the students of the sample. This is true because the students found most of the statements pertaining to dishonest behaviour either somewhat unacceptable or completely unacceptable.

\subsection{Students' level of academic honesty}

This factor analysis dealt with students' level of academic honesty and was measured using questions pertaining to cheating behaviours. The questions aimed to determine the students' level of academic honesty, and students were provided with the following possible responses: 1 = 'completely acceptable'; 2 = 'somewhat acceptable'; 3 = 'neither acceptable not unacceptable'; $4=$ 'somewhat unacceptable'; and $5=$ 'completely unacceptable'. A high value on this factor indicates a high level of academic honesty.

Table 3: Pattern matrix - level of academic honesty

\begin{tabular}{|l|c|}
\hline & Factor \\
\cline { 2 - 2 } & $\mathbf{1}$ \\
\hline 1. Getting someone else to write a test for you & 0.958 \\
\hline 2. Copying work from another student during a test or exam & 0.704 \\
\hline 3. Taking notes into a test or exam & 0.598 \\
\hline 4. Copying sentences from the published work of others without citing the author & 0.579 \\
\hline 5. Using some else's ideas as your own & 0.563 \\
\hline 6. Utilising the internet to find the assignments of others to use as your own & 0.521 \\
\hline 7. Handing in an assignment identical to that of your friends & 0.517 \\
\hline Cronbach's alpha Factor $1=0.834$ & \\
\hline
\end{tabular}


Figure 4 indicates that the distribution of the sample responses for students' level of academic honesty is positively skewed. The mean of responses for students' level of academic honesty was 4.76, thus students generally considered acts of academic dishonesty as unacceptable, indicating a high level of agreement amongst the sample on what constitutes academic honesty.

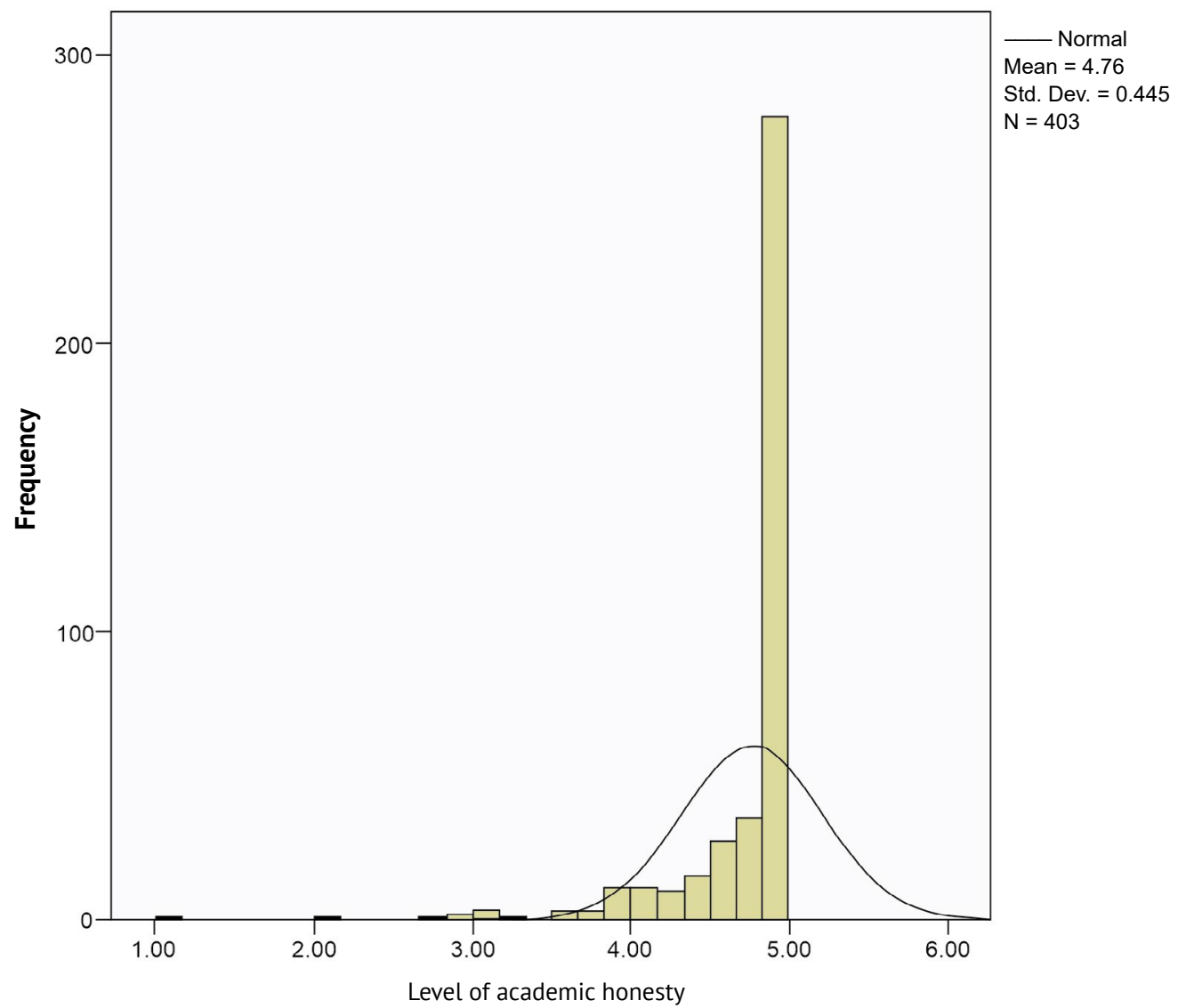

Figure 4: Histogram - level of academic honesty

One factor has been identified: level of academic honesty. The students constituting the sample had a very high level of academic honesty. They generally found the behaviours associated with academic dishonesty to be unacceptable.

\subsection{Justification of dishonest behaviours}

This factor analysis dealt with justifications for committing academic dishonesty and was measured using questions pertaining to how acceptable students find justifications for academically dishonest behaviours. The questions aimed to determine to what extent the students justified reasons for improper academic behaviour, and students were provided with the following possible responses: 1 = 'completely acceptable'; 2 = 'somewhat acceptable'; 3 = 'neither acceptable not unacceptable'; 4 = 'somewhat unacceptable'; and 
5 = 'completely unacceptable'. Students who achieve a high score on this factor are not accepting of justifications for academic dishonesty.

Table 4: Pattern matrix - justification of dishonest behaviours

\begin{tabular}{|l|c|}
\hline & Factor \\
\cline { 2 - 2 } & $\mathbf{1}$ \\
\hline 1. There is pressure from the students' peers to do well & 0.851 \\
\hline 2. The student is trying to improve their poor marks & 0.846 \\
\hline 3. The student has to compete with other students & 0.831 \\
\hline 4. There is pressure from students' parents to do well & 0.819 \\
\hline 5. The student only behaves this way when it is absolutely necessary & 0.762 \\
\hline 6. This student doesn't behave this way often & 0.697 \\
\hline 7. The student is influenced by a fear of failure & 0.668 \\
\hline 8. No-one else is hurt by the students' behaviour & 0.664 \\
\hline 9. There is a lack of time to adequately prepare for an assessment & 0.652 \\
\hline 10. The student behaves this way because others are behaving this way too & 0.602 \\
\hline Cronbach's alpha Factor $1=0.924$ & \\
\hline
\end{tabular}


Figure 5 indicates that the distribution of the sample responses for the justifications of academic dishonesty is not normally distributed. The mean of responses for the justifications of academic dishonesty was 3.38. However, whilst the mean is located around the average point, it is not a good description of the sample. This is due to a fairly large standard deviation which indicates a lot of variability in the scores. Some of the students do find the justifications for academic dishonesty somewhat unacceptable, whilst others find it acceptable.

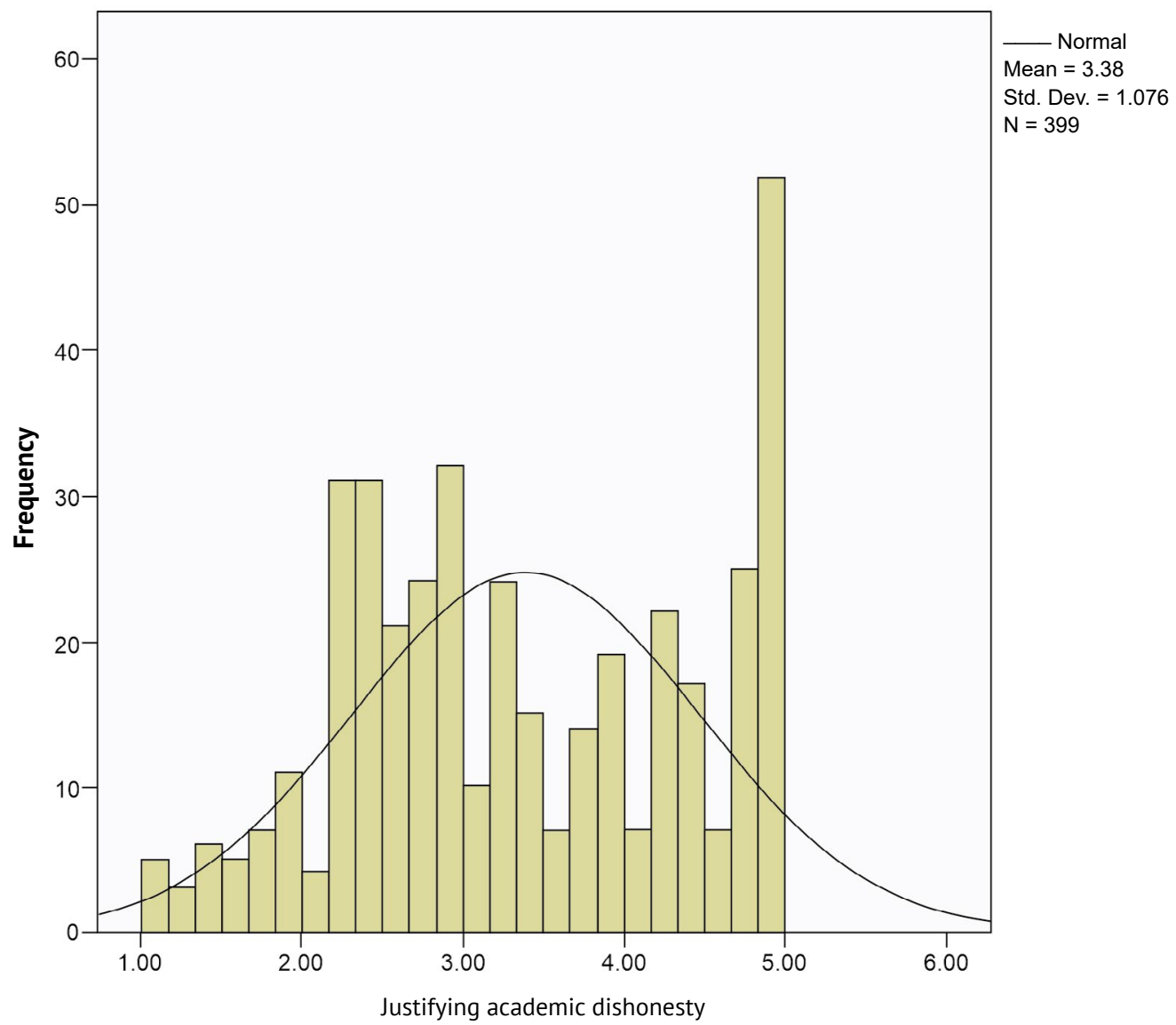

Figure 5: Histogram - justification of dishonest behaviours

One factor has been identified: justifications for academic dishonesty. The students were gravitating towards finding the majority of the statements somewhat unacceptable (their responses were located between 'neither acceptable nor unacceptable' and 'somewhat unacceptable'). The mean of the students is located around a general neutrality towards the justifications for academic dishonesty. However, due to a fairly large standard deviation, the mean is not a good description of the sample. Some students find the justifications for academic dishonesty somewhat unacceptable whilst others find it acceptable. 


\subsection{Justification of reporting or not reporting}

This factor analysis dealt with the motivations for reporting or not reporting academic dishonesty. The questions aimed to determine why students justify reporting or not reporting academic dishonesty. The students were asked how influential certain factors were when considering reporting academic dishonesty and were provided with the following set of possible responses: 1 = 'extremely influential'; 2 = 'somewhat influential'; $3=$ 'slightly influential'; and $4=$ 'not influential at all'. The factor analysis and item analysis on this set of items provided two factors: one that indicated the influence of a possible personal impact when deciding to report academic dishonesty, and one that reflected the influence of adherence to principles when deciding whether to report academic dishonesty. A low score on both these factors indicated that the factor was very influential in deciding whether to blow the whistle.

Table 5: Pattern matrix - justification of reporting or not reporting

\begin{tabular}{|c|c|c|}
\hline & \multicolumn{2}{|c|}{ Factor } \\
\hline & 1 & 2 \\
\hline 1. Fear of victimisation from other students if I report cheating & 0.871 & \\
\hline 2. Concern that students will retaliate if I report their cheating behaviour & 0.843 & \\
\hline $\begin{array}{l}\text { 3. A perception that students who report on friends that cheat are said to be } \\
\text { disloyal }\end{array}$ & 0.738 & \\
\hline $\begin{array}{l}\text { 4. A perception that students who 'tell on' other students tend to have no } \\
\text { friends at university }\end{array}$ & 0.728 & \\
\hline $\begin{array}{l}\text { 5. Concern that reporting on students that cheat might ruin my relationship with } \\
\text { those students }\end{array}$ & 0.658 & \\
\hline 6. Fear of the repercussions from blowing the whistle & 0.504 & \\
\hline 7. My belief that it is important to adhere to academic rules and regulations & & 0.869 \\
\hline 8. My belief that academic dishonesty is a serious offence 0.819 & & 0.819 \\
\hline $\begin{array}{l}\text { 9. My view that cheating behaviour damages the reputation of your academic } \\
\text { institution }\end{array}$ & & 0.689 \\
\hline 10. My belief that students who cheat create an unfair advantage for themselves & & 0.524 \\
\hline
\end{tabular}


Figure 6 indicates that the distribution of the sample responses for the justification of not reporting academic dishonesty (the personal impact reporting might have) is positively skewed. The mean of responses for the willingness to report severe academic dishonesty was 2.32 , thus the average student found the personal impact of reporting at least somewhat influential when deciding whether to report wrongdoing.

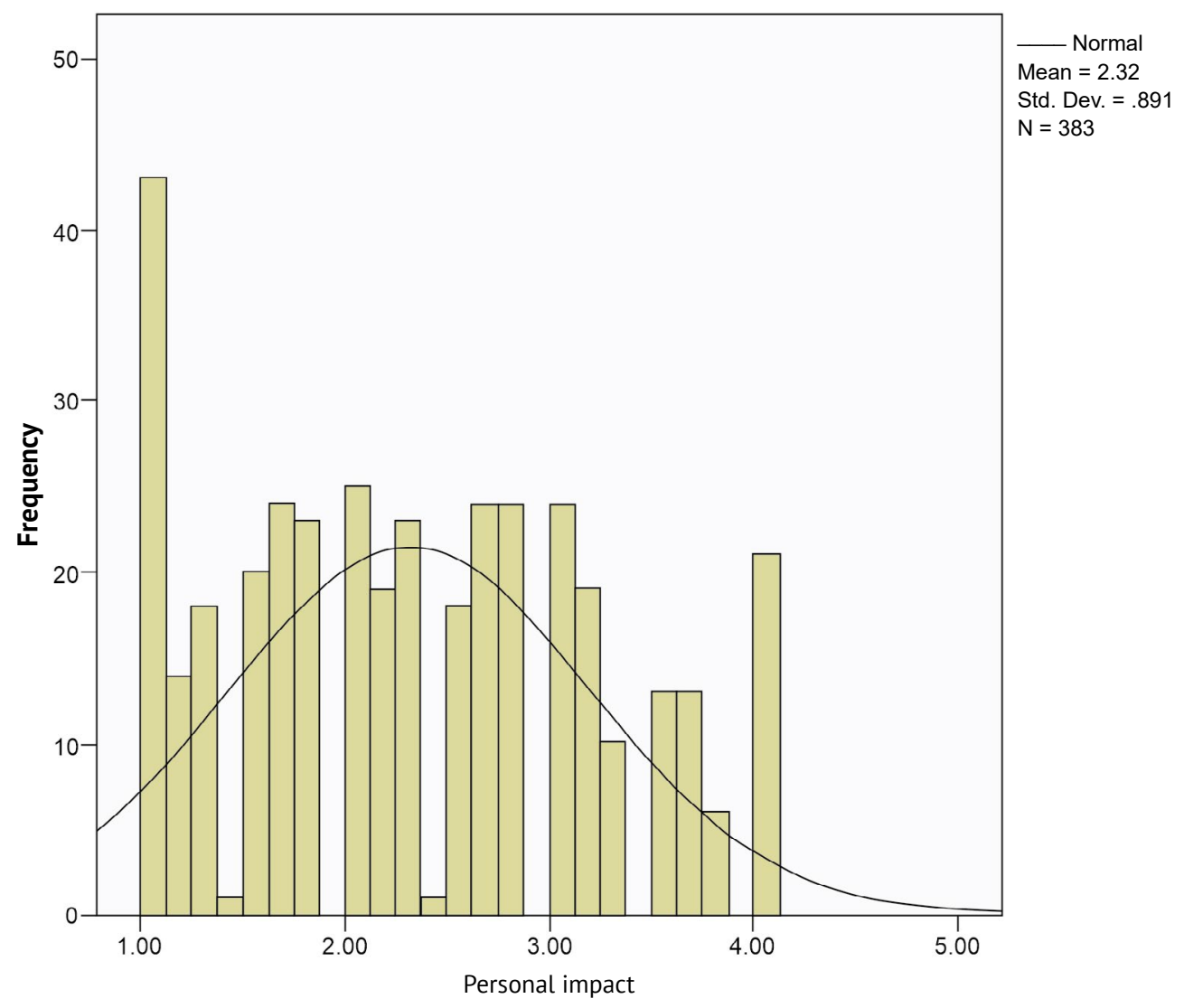

Figure 6: Histogram - personal impact 
Figure 7 indicates that the distribution of the sample responses for the justification of reporting academic dishonesty (adherence to principles) is positively skewed. The mean of responses for the willingness to report severe academic dishonesty was 1.55 , which means adherence to principles is somewhat influential in students' decision-making regarding reporting academic dishonesty.

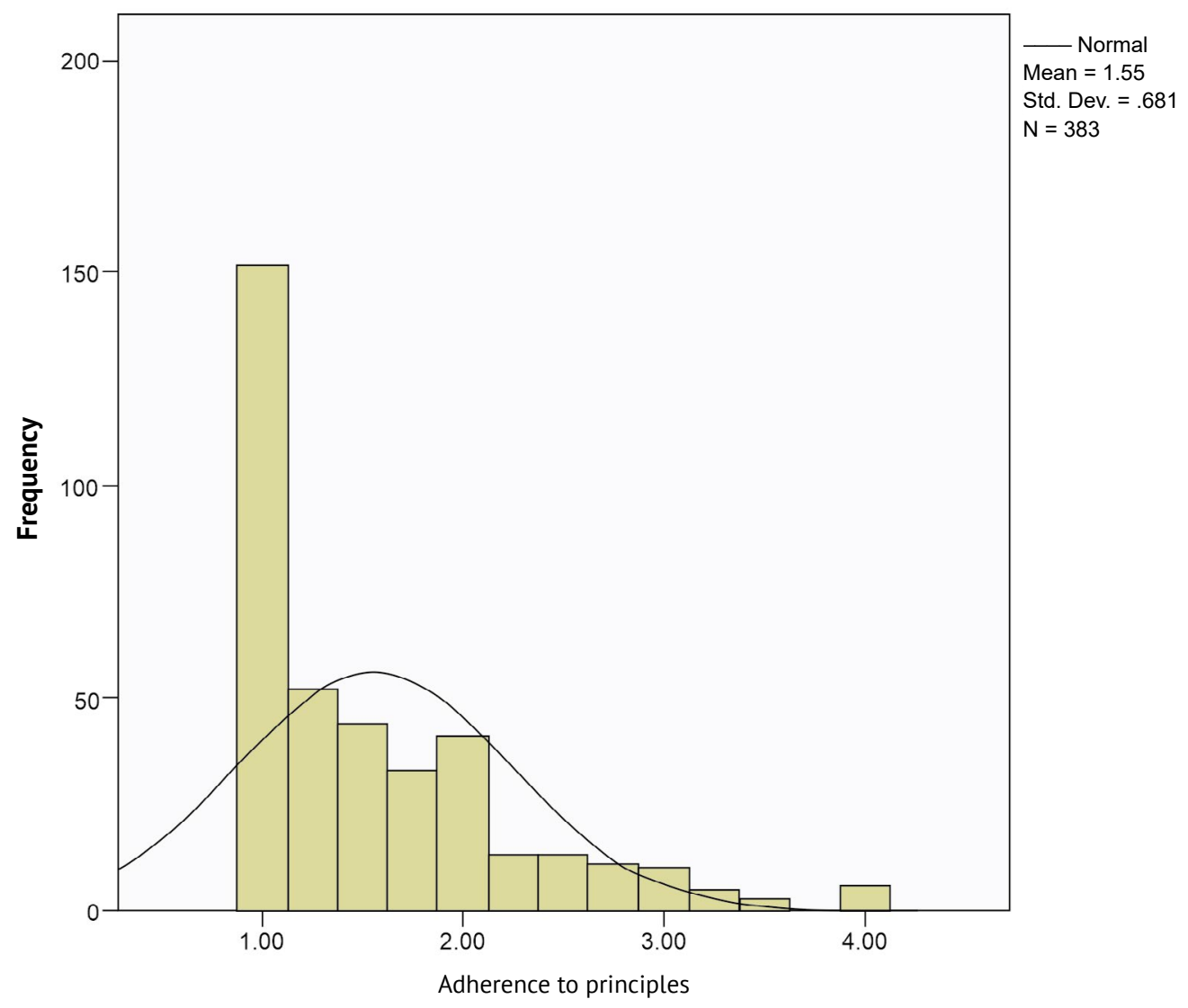

Figure 7: Histogram - adherence to principles

Two factors were identified: the personal impact of reporting academic dishonesty and adherence to principles as being influential when reporting academic dishonesty. The possible personal impact of reporting academic dishonesty is somewhat influential in students' decisions to report or not report academic dishonesty. It is mainly impacted by a fear of retaliation from the wrongdoer and student community. Adherence to principles is influential in students' decisions to report academic dishonesty. Students feel that rules, norms and procedures are influential in making their decisions with regard to reporting academic dishonesty.

The dependent variable reflects two variables associated with it, namely the willingness to report severe academic dishonesty and the willingness to report less severe academic dishonesty. The independent variables are: level of general honesty; level of academic honesty; the extent to which dishonest behaviours are justified; the extent to which the 
possible personal impact of reporting academic dishonesty is considered when deciding to report; and the extent to which adherence to principles is considered when deciding whether to report. The relationship between the willingness to report severe and less severe academic dishonesty and the independent variables was then tested.

\subsection{Hypothesis testing}

The correlations between the dependent and independent variables are reflected in Table 6.

Table 6: Pearson's $r$-hypothesis tests

\begin{tabular}{|c|c|c|c|}
\hline & & $\begin{array}{c}\text { Severe } \\
\text { academic } \\
\text { dishonesty }\end{array}$ & $\begin{array}{c}\text { Less severe } \\
\text { academic } \\
\text { dishonesty }\end{array}$ \\
\hline \multirow[t]{3}{*}{ 1. General honesty } & Pearson correlation & 0.352 & 0.348 \\
\hline & Sig. (2-tailed) 0.0000 .000 & 0.000 & 0.000 \\
\hline & $\mathrm{N}$ & 405 & 405 \\
\hline \multirow[t]{3}{*}{ 2. Level of academic honesty } & Pearson correlation & 0.241 & 0.197 \\
\hline & Sig. (2-tailed) 0.0000 .000 & 0.000 & 0.000 \\
\hline & $\mathrm{N}$ & 403 & 403 \\
\hline \multirow[t]{3}{*}{ 3. Justifying academic dishonesty } & Pearson correlation & 0.180 & 0.069 \\
\hline & Sig. (2-tailed) 0.0000 .000 & 0.000 & 0.170 \\
\hline & $\mathrm{N}$ & 399 & 399 \\
\hline \multirow[t]{3}{*}{ 4. Personal impact } & Pearson correlation & 0.104 & -0.012 \\
\hline & Sig. (2-tailed) 0.0000 .000 & 0.042 & 0.812 \\
\hline & $\mathrm{N}$ & 383 & 383 \\
\hline \multirow[t]{3}{*}{ 5. Adherence to principles } & Pearson correlation & -0.352 & -0.245 \\
\hline & Sig. (2-tailed) 0.0000 .000 & 0.000 & 0.000 \\
\hline & $\mathrm{N}$ & 383 & 383 \\
\hline
\end{tabular}

Table 6 indicates that there is a statistically significant correlation between the students' general honesty and their willingness to report academic dishonesty as the $p$-value is $<0.0005$. The correlation between level of general honesty and the willingness to report both severe and less severe academic dishonesty, is moderate as the Pearson's $r$-values are 0.352 and 0.348 respectively. Students who scored low on the factor 'general honesty' typically also scored low on the willingness to report severe and less severe academic dishonesty. Thus, students who are generally more dishonest are less willing to report academic dishonesty. Therefore, there is a moderate statistically significant correlation between levels of general honesty and the willingness to report severe academic dishonesty as well as less severe academic dishonesty.

There is also a statistically significant correlation between students' level of academic honesty and the willingness to report both severe and less severe academic dishonesty as the $p$-values are both $<0.0005$. While significant, the correlation between students' level of academic dishonesty and their willingness to report both severe and less severe 
academic dishonesty is small, as the Pearson's $r$-values are 0.241 and 0.197 respectively. Both severe academic dishonesty and less severe academic dishonesty correlate positively with the factor 'level of academic honesty'. Students who have a low level of academic honesty are less willing to report academic dishonesty and students with a high level of academic honesty are more willing to report academic dishonesty. Hence, there is a small statistically significant correlation between students' level of academic honesty and the willingness to report severe academic dishonesty as well as less severe academic dishonesty.

The correlation between the extent to which students justify academic dishonesty and their willingness to report less severe academic dishonesty is not significant ( $p$-value $=0.170$ ). However, there is a statistically significant correlation between the justification of dishonest behaviours and the willingness to report severe academic dishonesty as the $p$-value is $<0.0005$. Therefore, the greater the extent to which students justify academic dishonesty the less willing they are to report severe academic dishonesty, while students who do not justify academic dishonesty are also more willing to report severe academic dishonesty. With a Pearson's $r$-value of 0.180 this correlation is small. Justifications for academic dishonesty therefore do not seem to play a very important role in deciding whether to report wrongdoing.

When testing the influence of the personal impact of reporting academic dishonesty against the willingness to report less severe academic dishonesty, no significant correlation was found ( $p$-value $=0.812$ ). There is a statistically significant correlation between the extent to which the possible personal impact of reporting academic dishonesty influences students' decision with regard to reporting and their willingness to report severe academic dishonesty. The $p$-value of 0.042 shows a statistically significant relationship between the weak positive correlation found between the influence of possible personal impacts of reporting academic dishonesty and their willingness to report severe academic dishonesty. This indicates that the less influenced students are by the fear of personal repercussions, the more willing they are to report severe academic dishonesty. It is important to remember that this correlation is very low. Therefore, there is a statistically significant correlation between the personal impact of reporting academic dishonesty and the willingness to report severe academic dishonesty.

Finally, Table 6 also indicates the influence of adherence to principles when reporting academic dishonesty tested against the willingness to report severe academic dishonesty. A statistically significant negative correlation was found between the influence of adherence to principles and the willingness to report on severe academic dishonesty as well as less severe academic dishonesty ( $p$-value $<0.0005)$. In the case of willingness to report severe academic dishonesty the correlation is moderate (Pearson's $r$-correlation indicates a moderate negative correlation (-0.352)). The correlation between the influence of adherence to principles and students' willingness to report less severe academic dishonesty is small (Pearson's $r$-value $=-0.245$ ). Seeing that a low score on this factor indicates that adherence to principles is very influential in deciding whether to report academic dishonesty, it therefore can be concluded that the adherence to principles (such 
as institutional rules, norms and procedures) are influential in determining an individual's willingness to report both severe and less severe forms of academic dishonesty. Thus, there is a statistically significant negative correlation between the adherence to principles and the willingness to report severe academic dishonesty as well as less severe academic dishonesty.

\section{Discussion}

Jubb (1999:78) had identified that whistle-blowing tends to occur when an individual develops an ethical dilemma upon the witnessing of wrongdoing in any given organisation. Uys and Senekal (2008) had identified a morality of loyalty to an institution as a precursor to the reporting of wrongdoing. Therefore, themes that govern an individual's degrees of morality and its association to the willingness to report wrongdoing are rife. This study identified the relationship between general honesty and the willingness to report academic dishonesty.

This study has indicated that there is a statistically significant correlation between general honesty and the willingness to report academic dishonesty. Therefore, it can be concluded that an individual's degree of morality tends to impact on their willingness to report academic dishonesty. This is supported by the reasoned action approach which illustrates that individual background factors such as values (general honesty) impact on normative beliefs (a belief that general dishonest behaviour is acceptable), which in turn impacts on the attitude (an attitude of accepting academic cheating as normal) which predicts the intention (not being willing to report academic dishonesty). This research identified that students who exhibit lower degrees of general honesty are less willing to report academic dishonesty, whilst students with a higher degree of general honesty are more willing to report academic dishonesty. Hence, this research concurs with established literature that morality impacts on an individual's likelihood to report academic dishonesty (Henningsen et al., 2013).

This study determined that there is a statistically significant correlation between students' level of academic honesty and the willingness to report academic dishonesty. This means that having a higher level of academic honesty plays a pivotal role in the willingness to report academic dishonesty. This coincides with the reasoned action approach, as it identified individual background factors (such as values) as having a significant impact on beliefs that influence the willingness to report academic dishonesty (Fishbein \& Ajzen, 2010:18). Students who exhibit a lower level of academic honesty (having lower-set values) are less likely to report it. Those students with a higher level of academic honesty (having higher-set values) are more likely to report academic dishonesty.

Literature has indicated that students justify academic dishonesty due to a "fear of failure" (Monica et al., 2010). The research indicated that there is a statistically significant correlation between the justifications of academically dishonest behaviours and the willingness to report the severe academic dishonesty. Students who justified academic dishonesty were less likely to report severe academic dishonesty, such as test cheating. 
Wrongdoer retaliation has been identified as an integral variable that discourages individuals from blowing the whistle (Black, 2011). This study indicated that a statistically significant correlation exists between the personal impact of reporting academic dishonesty and the willingness to report severe academic dishonesty. This relates to the notion of 'fear of retaliation', as identified in the literature. The research identified that the less fearful students are of personal repercussions (such as retaliation), the more willing they are to report severe academic dishonesty. Conversely, the more students are influenced by a fear of reprisals, the less willing they are to report academic dishonesty. Students, essentially, weigh up the personal impact that the act of whistle-blowing will have on their lives (this can be victimisation and ostracising), and if they deem the impact influential enough, they will not report the academic transgressions. This relates to the individual background factor of perceived risk in the reasoned action approach. Perceived risk directly influences one's beliefs which predict the intention to act. Herein, the perceived risk influences the reporting of severe academic dishonesty.

An individual's loyalty to an organisation should be a good predictor of whether they would report wrongdoing within that given organisation (Uys \& Senekal, 2008:38). This is evident in the reasoned action approach, as the environmental factors, which in this study are the rules, norms and regulations, act as an actual control that influences behaviour. Thus, it can be noted that the research largely concurs with the literature that an adherence to principles influences an individual's willingness to report. If a student feels that academic dishonesty is a serious offence, which damages the reputation of their university, and goes against its rules, and regulations - that student would likely be willing to report the academic dishonesty.

\section{Conclusion}

Literature indicated that academic dishonesty is a problem prevalent in both global and local institutions, and whistle-blowing presented itself as a mechanism to curb academic dishonesty. The theoretical framework was located in the reasoned action approach, which illustrated how various factors and beliefs influenced the propensity to report academic dishonesty.

The research concurred with literature that varying degrees of morality impact on a student's willingness to report academic dishonesty, because students with higher degrees of general honesty were more willing to report academic dishonesty. Students who had a lesser level of academic honesty were less willing to report severe and less severe academic dishonesty. Furthermore, students who justify academic dishonesty are less willing to report it. The personal impacts of reporting academic dishonesty influence the willingness to report severe academic dishonesty. Lastly, the adherence to principles influences a student's willingness to report. Importantly, the research indicated (across all factors) that the willingness to internally report academic dishonesty was generally not common amongst this group of sociology undergraduate students. 
The following recommendations can be made to improve possible future research:

i. This study focused on sociology undergraduate students. Should future researchers wish to conduct a more comprehensive study, they could consider that a population is selected that encompasses students from a varied array of subjects and faculties, and not just the field of sociology. Furthermore, they should also include postgraduate students along with undergraduate students. In targeting a diverse student population, the responses would be more representative of general student perceptions.

ii. A mixed methods approach could be considered to improve the research as it would enable the researcher to yield large quantities of responses from quantitative research, as well as more descriptive attitudes, beliefs and feelings regarding the topic via qualitative research. The qualitative element of research would assist in a more detailed understanding of factors contributing to reporting academic dishonesty, and whether their individual opinions of cheating behaviours differ.

\section{References}

Black, L.M. (2011). Tragedy into Policy: A Quantitative Study of Nurses' Attitudes toward Patient Advocacy Activity. The American Journal of Nursing, 111(6):26-35. https://doi.org/10.1097/01.NAJ.0000398537.06542.c0

Bourque, L. \& Fielder, E. (2003). How to Conduct Self-administered and Mail Surveys. Thousand Oaks, CA: Sage. https://doi.org/10.4135/9781412984430

Callahan, E.S. \& Collins, J.W. (1992). Employee Attitudes toward Whistle-blowing: Management and Public Policy Implications. Journal of Business Ethics, 11(12):939-948. https://doi.org/10.1007/BF00871960

De Bruin, G.P. \& Rudnick, H. (2007). Examining the Cheats: The Role of Conscientiousness and Excitement Seeking in Academic Dishonesty. South African Journal of Psychology, 37(1):153-164. https://doi.org/ 10.1177/008124630703700111

De Lambert, K., Ellen, N. \& Taylor, L. (2003). Cheating - What Is It and Why Do It: A Study in New Zealand Tertiary Institutions of the Perceptions and Justifications for Academic Dishonesty. Journal of American Academy of Business, 3(1/2):98-103.

Department of Student Ethics and Judicial Services. (2014). Report for the 1st and 2nd Quarters of 2014. Johannesburg: University of Johannesburg.

De Winter, J.C.F. \& Dodou, D. (2012). Factor Recovery by Principal Axis Factoring and Maximum Likelihood Factor Analysis as a Function of Factor Pattern and Sample Size. Journal of Applied Statistics, 39(4):695-710. https://doi.org/10.1080/02664763.2011.610445

Eastman, K.L., Eastman, J.K. \& Iyer, R. (2008). Academic Dishonesty: An Exploratory Study Examining Whether Insurance Students are Different from Other College Students. Risk Management and Insurance Review, 11(1):209-226. https://doi.org/10.1111/j.1540-6296.2008.00138.x

Eiselen, R. \& Uys, T. (2016). Analysing Survey Data using SPSS version 22: A Workbook. 5th edition. Johannesburg: University of Johannesburg.

Elliston, F.A. (1982). Anonymity and Whistleblowing. Journal of Business Ethics, 1(3):167-177. https://doi. org/10.1007/BF00382768

Finchilescu, G. \& Cooper, A. (2018). Perceptions of Academic Dishonesty in a South African University: A Q-Methodology Approach. Ethics and Behavior, 28(4):284-301. https://doi.org/10.1080/10508422.2017. 1279972 
Fishbein, M. \& Ajzen, I. (2010). Predicting and Changing Behavior: The Reasoned Action Approach. New York: Psychology Press. https://doi.org/10.4324/9780203838020

Henningsen, M.L.M., Valde, K.S. \& Denbow, J. (2013). Academic Misconduct: A Goals-Plans-Action Approach to Peer Confrontation and Whistle-Blowing. Communication Education, 62(2):148-168. https://doi.org/10.10 80/03634523.2012.752509

Hutton, P.A. (2006). Understanding Student Cheating and What Educators Can Do about It. College Teaching, 54(1):171-176. https://doi.org/10.3200/CTCH.54.1.171-176

Jubb, P.B. (1999). Whistleblowing: A Restrictive Definition and Interpretation. Journal of Business Ethics, 21(1):77-94. https://doi.org/10.1023/A:1005922701763

Larmer, R.A. (1992). Whistleblowing and Employee Loyalty. Journal of Business Ethics, 11(2):125-128. https:// doi.org/10.1007/BF00872319

Lewis, D., Ellis, C.A., Kyprianou, A. \& Homewood, S. (2001). Whistleblowing at Work: The Results of a Survey of Procedures in Further and Higher Education. Education and the Law, 13(3):215-225. https://doi.org/ 10.1080/09539960127292

McCabe, D.L. \& Trevino, L.K. (1997). Individual and Contextual Influences on Academic Dishonesty: A Multicampus Investigation. Research in Higher Education, 38(3):379-396. https://doi.org/10.1023/ A: 1024954224675

McCabe, D.L., Trevino, L.K. \& Butterfield, K.D. (2001). Dishonesty in Academic Environments: The Influence of Peer Reporting Requirements. The Journal of Higher Education, 72(1):29-45. https://doi.org/10.1080/00 221546.2001.11778863

Mesmer-Magnus, J.R. \& Viswesvaran, C. (2005). Whistleblowing in Organizations: An Examination of Correlates of Whistleblowing Intentions, Actions, and Retaliation. Journal of Business Ethics, 62(3):277-297. https://doi.org/10.1007/s10551-005-0849-1

Miceli, M.P. \& Near, J.P. (1992). Blowing the Whistle: The Organizational and Legal Implications for Companies and their Employees. New York, NY: Lexington Books.

Monica, M., Ankola, A.V., Ashokkumar, B.R. \& Hebbal, I. (2010). Attitude and Tendency of Cheating Behaviours amongst Undergraduate Students in a Dental Institution of India. European Journal of Dental Education, 14:79-83. https://doi.org/10.1111/j.1600-0579.2009.00592.x

Rabi, S.M., Patton, L.R., Fjortoft, N. \& Zgarrick, D.P. (2006). Characteristics, Prevalence, Attitudes, and Perceptions of Academic Dishonesty among Pharmacy Students. American Journal of Pharmaceutical Education, 70(4):1-8. https://doi.org/10.5688/aj700473

Rennie, S.C. \& Crosby, J.R. (2001). Are "Tomorrow's Doctors" Honest? Questionnaire Study Exploring Medical Students' Attitudes and Reported Behaviour on Academic Misconduct. British Medical Journal, 322(7281):274-275. https://doi.org/10.1136/bmj.322.7281.274

Rennie, S.C. \& Rudland, J.R. (2003). Differences in Medical Students' Attitudes to Academic Misconduct and Reported Behaviour across the Years: A Questionnaire Study. Journal of Medical Ethics, 29(2):97-102. https://doi.org/10.1136/jme.29.2.97

Seals, M., Hammons, J.O. \& Mamiseishvili, K. (2014). Teaching Assistants' Preparation for, Attitudes Towards, and Experiences with Academic Dishonesty: Lessons Learned. International Journal of Teaching and Learning in Higher Education, 26(1):26-36.

Thomas, A. \& De Bruin, G.P. (2012). Student Academic Dishonesty: What do Academics think and do, and what are the Barriers to Action? African Journal of Business Ethics, 6(1):13-24. https://doi.org/10.4103/18177417.104698

Thomas, A. \& Van Zyl, A. (2012). Understanding of and Attitudes to Academic Ethics among First-year University Students. African Journal of Business Ethics, 6(2):143-155. https://doi.org/10.4103/18177417.111028

UJ (University of Johannesburg) (2013). Policy: Plagiarism. https://bit.ly/2OWV1j2 [Accessed 16 November 2016]. 
Uys, T. (2008). Rational Loyalty and Whistleblowing: The South African Context. Current Sociology, 56(6):904-921. https://doi.org/10.1177/0011392108095345

Uys, T. \& Senekal, A. (2008). Morality of Principle versus Morality of Loyalty: The Case of Whistleblowing. African Journal of Business Ethics, 3(1):38-44. https://doi.org/10.15249/3-1-74 